\title{
Vitamin D: missing link between hypertension and muscle mass
}

\author{
Maja Baretić ${ }^{1}$ Martina Matovinović ${ }^{1} \cdot$ Tea Vukić$^{2} \cdot$ Darjan Ranilović $^{2}$
}

Received: 31 May 2017 / Revised: 20 August 2017 / Accepted: 29 August 2017 / Published online: 20 November 2017

(C) Macmillan Publishers Limited, part of Springer Nature 2018

We have read 'Effects of calcium plus vitamin D supplementation on blood pressure: a systematic review and metaanalysis of randomised controlled trials' and have shared our experiences with vitamin D and hypertension [1]. We retrospectively analysed data of 33 obese patients attending a structural educational programme at the Department of Endocrinology, Internal Medicine Clinic, University Hospital Centre Zagreb, Croatia. Two groups were included. Group 1: 16 patients with hypertension (3 males; 13 females; average body mass index (BMI), $38 \mathrm{~kg} / \mathrm{m}^{2}$; median age, 40 years) and Group 2: 17 patients without hypertension (4 males; 13 females; average BMI, $45 \mathrm{~kg} / \mathrm{m}^{2}$; median age, 45 years). Secondary causes of obesity were excluded (normal values of thyroid-stimulating hormone and cortisol after overnight suppression with $1 \mathrm{mg}$ dexamethasone), and no participant took vitamin D supplements. Body composition was estimated by bioelectrical impedance analysis (fat percentage, fat mass, muscle mass and visceral fat rating). Statistical analysis was performed on the age, sex, BMI, body composition, glucose, lipid profile and vitamin D level. Both groups had low vitamin D levels. In Group 1, the median vitamin D level was $40 \mathrm{nmol} / \mathrm{l}(20-69)$ and in Group 2, it was $36 \mathrm{nmol} / 1$ (12-76). A two-sided $t$-test revealed no significant difference in vitamin $D$ levels between the two groups $(P=0.343)$. In Group 1 , vitamin $\mathrm{D}$ levels positively correlated with muscle mass (Spearman's correlation coefficient, $r=0.68$ ); however, this correlation was insignificant in Group $2(r=-0.32)$. Whether this finding was accidental or some pathophysiological explanation existed, i.e., were there connectors linking vitamin D action, hypertension and muscle mass remains unknown.

Vitamin D influences muscles by the following pathways: (a) genetic, mediated by a receptor present in muscle cells and (b) nontranscriptional, which cannot be explained

Maja Baretić

maja.simek@zg.t-com.hr

1 Internal Clinic, Department of Endocrinology, University Hospital Centre Zagreb, Zagreb, Croatia

2 School of Medicine, University of Zagreb, Zagreb, Croatia by a slow genetic pathway. Vitamin D promotes mitogenactivated protein kinase (MAPK) signalling pathway activation, resulting in myogenesis initiation, cell proliferation, differentiation and apoptosis [2]. MAPK is activated by various stimuli, including angiotensin II [3]. MAPK signalling plays a bigger role in adipogenesis; after stimulation, transcriptional pathways are initiated to ensure terminal differentiation of precursors into adult white or brown adipocytes [4]. Vitamin D is associated with metabolic syndrome, hypertension and muscle mass, probably by MAPK signalling pathway. Postreceptor pathways mediated by vitamin $\mathrm{D}$ influence both metabolic syndrome and body composition elements (hypertension and muscle mass). For obese hypertensive patients, assessing only BMI is not enough because it does not reveal sarcopenic obesity. Hitherto, the type of patients with hypertension and low vitamin D level who would benefit from vitamin D substitution therapy has not been determined. In an analysis of 92 subjects with low baseline vitamin D levels ( $<79.9 \mathrm{nmol} / \mathrm{l})$, significant decreases in 24-h systolic and diastolic blood pressures occurred during cholecalciferol supplementation [5]. Since our group of hypertensive obese patients had much lower baseline vitamin D levels, they should certainly be given substitution therapy. Further research is warranted to confirm the effect magnitude of calcium and vitamin D supplementation on blood pressure changes, as stated in the article published in your journal [1].

\section{Compliance with Ethical Standards}

Conflict of interest The authors declare no conflict of interest.

\section{References}

1. Wu L, Sun D. Effects of calcium plus vitamin D supplementation on blood pressure: a systematic review and meta-analysis of randomized controlled trials. J Hum Hypertens. 2017;31:547-54.

2. Wu Z, Woodring PJ, Bhakta KS, Tamura K, Wen F, Feramisco JR, et al. p38 and extracellular signal-regulated kinases regulate the myogenic program at multiple steps. Mol Cell Biol. 2000;20:3951-64.

3. Ushio-Fukai M, Alexander RW, Akers M, Griendling KK. p38 Mitogen-activated protein kinase is a critical component of the 
redox-sensitive signaling pathways activated by angiotensin II. Role in vascular smooth muscle cell hypertrophy. J Biol Chem. 1998;273:15022-29.

4. Gehart H, Kumpf S, Ittner A, Ricci R. MAPK signalling in cellular metabolism: stress or wellness? EMBO Rep. 2010;11:834-40.
5. Larsen T, Mose FH, Bech JN, Hansen AB, Pedersen EB. Effect of cholecalciferol supplementation during winter months in patients with hypertension: a randomized, placebo78 controlled trial. Am J Hypertens. 2012;25:1215-22. 